JRI: Jurnal Rekayasa Industri, Vol. 1 No. 1 Oktober 2019

p-ISSN / e-ISSN

\title{
MODIFIKASI SPUYER PADA KOMPOR BIOGAS DR DAN PEMBERIAN KATUP PENGAMAN TEKANAN BIOGAS
}

\author{
Ilmardani Rince Ramli \\ Fakultas Teknik, Jurusan Teknik Industri, Universitas Widya Mataram \\ Dalem mangkubumen KT III/237 Yogyakarta \\ Email: daniramligallery@gmail.com
}

\begin{abstract}
ABSTRAK
Seiring perkembangan dan peradapan manusia serta dengan berjalanya waktu serta perkembangan ilmu pengetahuan manusia, kebutuhan hidup dan energipun berkembang kenaikan harga minyak dunia sangat berpengaruh terhadap kehidupan masyarakat Indonesia. Pemerintah segera mengambil langkah mengambil subsidi bahan bakar (BBM) dengan hal tersebut berdampak langsung kepada masyarakat desa yang sehari harinya membutuhkan energi untuk keperluan rumah tangga.dengan halterebut harus ada bahan bakar alternatif (terbarukan) untuk solosinya dengan Tehnologi tepat guna yang efektif, efisien dan ramah lingkungan yaitu dengan membuat alat BRT DR untuk memproses limbah kotoran sapi menjadi gas untuk keperluan sehari hari bagi masyarakat untuk memasak, energi listrik sesuai dengan situasi dan kondosi lingkungan masyarakat yang mempunyai bahan dasar limbah kotoran sapi, dapat memanfaatkan limbah kotoran sapi utuk diproses menjadi gas degan alat tepat guna. Dan memodifikasi spuyer pada kompor biogas serta memberi katup sebagai pengaman tekanan biogas.
\end{abstract}

Kata Kunci: modifikasi, spuyer, kompor biogas, katup pengaman

\begin{abstract}
Along with the development and appearance of human beings with the passage of time and the development of human science, life necessities and the evolving energy of the increase in world oil prices, it is very influential on the lives of Indonesian people. The government immediately took steps to take fuel subsidies with the direct impact on the community of the day-to-day needs of energy for household needs. With this, there must be alternative (renewable) fuels for their solutions with appropriate technology that is effective, efficient and friendly. environment by making a DR BRT tool to process cow manure into gas for daily needs for the community to cook, electricity in accordance with the situation and environment of the community which has the ingredients of cow dung waste, can utilize the cow manure to be processed into gas with appropriate tool. And modify spuyers on biogas stoves and provide valves as a safety measure for biogas pressure.
\end{abstract}

Keywords: modification, spuyer, biogas oven, safeguard valve 


\section{PENDAHULUAN}

Kenaikan harga bahan bakar minyak (BBM) akhir-akhir ini sangat membebani kehidupan masyarakat Indonesia terutama masyarakat petani dan petemak di pedesaan. Hal ini menjadi tantangan bagi semua komponen masyarakat untuk selalu mencari altematif bahan bakar murah dan mudah didapatkan sekaligus ramah lingkungan.Sekarang ini kotoran telah dianggap sebagai energi barn, yaitu sumber daya altematif yang bisa bermanfaat. Selain dimanfaatkan untuk pembuatan pupuk kandang dari kotoran hewan ternak, dan pupuk kompos dari sampah mmah tangga. Kotoran juga dimanfaatkan sebagai sumber daya altematif untukmemperoleh gas sebagai bahan bakar altematif yang dikenal sebagai biogas. Teknologi biogas ini memanfaatkan kotoran ternak yang jika diuraikan dalam kondisi kedap udara oleh bakteri anaerobik yang akan menghasilkan gas metana. Sebuah tabung plastik polyethylene digunakan untuk menampung kotoran ternak dalam kondisi kedap udara. Di dalam tabung plastik ini gas metana dihasilkan yang langsung dapat disalurkan dan dimanfaatkan sebagai bahan bakar.

Untuk menjaga keamanan instalasi biogas maka dipasanglah katup pengaman tekanan untuk menghindari tekanan berlebih pada reaktor dan reservoir yang terbuat dari drum dan mengingat bahwasanya biogas mengandung $\mathrm{H} 2 \mathrm{~S}$ yang mampu menyumbat spuyer kompor, maka perlu adanya modifikasi pada supyer biogas tersebut. Dari latar belakang diatas maka dapat diketahui masalah pada kompor biogas: Bagaimana cara membuat modifikasi pada spuyer kompor biogas dan bagaimana cara membuat katup pengaman tekanan secara sederhana. Tujuan penelitian ini agar kompor yang dimodifikasi ini dapat meminimalisir terjadinya korosi akibat $\mathrm{H} 2 \mathrm{~S}$ yang dihasilkan dari proses fermentasi biogas, dan juga dapat pemantau keamanan tekanan biogas.

\section{METODE PENELITIAN}

\subsection{Obyek Penelitian dan Subyek Penelitian}

1. Penelitian ini dilakukan di Desa Candi Abang, Sentonorejo Rt.06 Rw.06 Jogotirto Berbah Sleman.

2. Penelitian ini difokuskan pada pembuatan alat tepat guna modifikasi spuyer pada kompor biogas dan pemberian katup pengaman tekanan biogas (BRT DR) dengan bahan bakar limbah kotoran sapi

2.2 Alat bahan yang digunakan

1. spuyer kompor gas, pipa, lem pipa, toples, pipa siku.

2. Bor tangan, mesin las, mesin potong untuk pembuatan alat BRT DR

3. Limbah kotoran sapi

4. Camera digital untuk mendukumentasikan seluruh proses peneliti

2.3 Langkah langkah penelitian

1. Studi Pustaka

Studi ini dilakukan untuk mencari teori penelitianyang akan membantu menarik kesimpulan dari studi lapangan dan pemecahan masalah.

2. Indentifikasi Masalah

Berdasarkan pertimbangan hasil study lapangan dan study pustaka yang telah dilakukan sehingga dapat ditemukan rumusan permasalahan yang akan dipecahkan dalam penelitian ini, yaitu bagaimana cara memodifikasi spuyer kompor biogas dan memberikan katup pengaman tekanan.

3. Pengumpulan data

Tahapan ini sebagian besar merupakan tindak lanjut dari fase sebelumnya.Setelah permasalahan dan tujuan yang hendak dicapai,diindentifikasi, berdasarkan teori pendukung dilakukan pengumpulan data yang berkaitan dengan obyek dan metode penelitian.Data data yang dibutuhkan meliputi, tekanan biogas dan nyala kompor biogas.

4. Perancangan Model 
JRI: Jurnal Rekayasa Industri, Vol. 1 No. 1 Oktober 2019

Pada tahap ini akan dilakukan perancangan model spuyer dan katup pengman tekanan.

5. Pengujian dan Analisis Model

Apabila model telah diyatakan valid selanjutnya dilakukan pengujiandengan menyalakan kompor tesebut dan melihat indicator katup tekanan

6. Kesimpulan dan Saran

Bagian ini merupakan bagian penutup yang berisi kesimpulan mengenai sebuah hasil kegiatan penelitian yang dilakukan pada alat tepat guna BRT DR 6 dengan memberi katup pengaman tekanan biogas untuk memproses limbah kotoran sapi menjadi gas menthan untuk skala rumah tangga.

\subsection{Diagram penelitian}

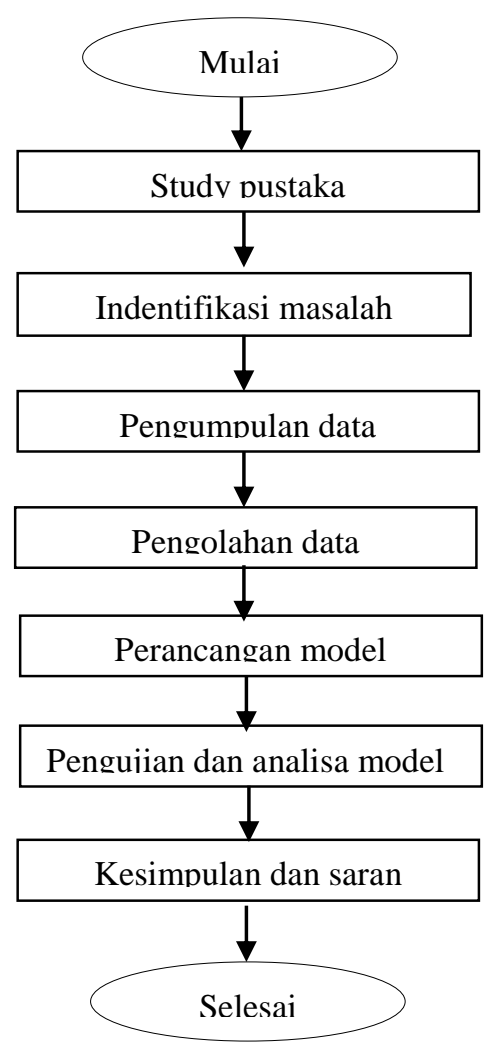

Gambar 1. Diagram alir penelitian

\section{HASIL DAN PEMBAHASAN}

\section{A. Modifikasi Pada Spuyer}

Modifikasi dilakukan pada spuyer biogas ini dengan membuat lubang pada nozzle berukuran lebih besar dengan spuyer yang dipakai pada kompor gas biasa. Hal ini dikarenakan adanya bahan seperti sulfur yang dapat menyebabkan penyumbatan pada spuyer tersebut. Dan spuyer diusahakan harus 
JRI: Jurnal Rekayasa Industri, Vol. 1 No. 1 Oktober 2019 p-ISSN / e-ISSN

berbahan kuningan untuk mengurangi proses oksidasi yang menyebabkan spuyer cepat berkarat dan keropos.

\section{B. Pemberian Katup Pengaman Tekanan Biogas}

Hasil pengukuran tekanan yang dihasilkan oleh biogas dapat dilihat pada Tabel 1.

Tabel 1. Tekanan Hasil Pengukuran

\begin{tabular}{|c|c|}
\hline Hari & Tekanan (Pa) \\
\hline 1 & 101334,77 \\
\hline 2 & 101324,31 \\
\hline 3 & 101383,61 \\
\hline 4 & 101417,80 \\
\hline 5 & 101461,76 \\
\hline 6 & 101500,84 \\
\hline 7 & 101549,68 \\
\hline 8 & 101603,41 \\
\hline 9 & 101642,49 \\
\hline 10 & 101676,68 \\
\hline 11 & 101701,10 \\
\hline 12 & 101705,98 \\
\hline 13 & 101735,29 \\
\hline 14 & 101769,48 \\
\hline 15 & 101808,56 \\
\hline 16 & 101832,98 \\
\hline 17 & 101867,17 \\
\hline 18 & 101891,59 \\
\hline 19 & 102165,12 \\
\hline 20 & 101964,86 \\
\hline
\end{tabular}


JRI: Jurnal Rekayasa Industri, Vol. 1 No. 1 Oktober 2019

Pembuatan katup pengaman tekanan

Data yang diperoleh dari reaktor biogas didapat bahwa tekanan maksimal yang di hasilkan adalah 841 Pa selisih dari (102165,12 Pa - $101325 \mathrm{~Pa})$, dengan kekuatan ijin plastik polyethelene di ketahui 1000 $\mathrm{Pa}$ (Indartono, 2005). Dengan menggunakan persamaan di bawah. maka tinggi kolom air yang dipergunakan untuk menjaga tekanan di reaktor agar tidak melebihi kekuatan plastik polyethelene adalah:

$$
\begin{aligned}
& \text { P = p.g.h } \\
& \text { P: tekanan } \\
& \text { p: massa jenis benda } \\
& \text { g : gaya gravitasi bumi } \\
& \text { h : ketinggian } \\
& 840 \mathrm{~kg} / \mathrm{m} \cdot \mathrm{dt}^{2}-995,8 \mathrm{~kg} / \mathrm{m}^{3} \times 9,81 \mathrm{~m} / \mathrm{dt}^{2} \times \mathrm{h} \\
& \mathrm{h}=\frac{840 \mathrm{~kg} / \mathrm{m} \cdot \mathrm{dt}^{2}}{995,8 \mathrm{~kg} / \mathrm{m}^{3} \times 9,81 \mathrm{~m} / \mathrm{dt}^{2}} \\
& \quad=0,0859 \mathrm{~m}=8,59 \mathrm{~cm}
\end{aligned}
$$

Di temukan tinggi yang memadai untuk di tambahkannya air adalah $8,59 \mathrm{~cm}$.

Pada pengukuran tekanan biogas ini mengalami sedikit kendala karena tekanan biogas tidak terdeteksi, sehingga membuat penelitian ini memerlukan waktu yang sedikit lama.

\section{SIMPULAN}

Hasil modifikasi spuyer biogas yang telah dilakukan adalah dengan memperbesar lubang nozzle sehingga tidak terjadi penyumbatan. Selain itu, bahan yang digunakan untuk memodifikasi spuyer menggunakan bahan kuningan sehingga tidak mudah berkarat. Sedangkan penambahan katup pengaman tekanan menghasilkan tekanan sebesar $841 \mathrm{~Pa}$ supaya instalasi biogas aman, dan untuk menjaga tekanan dalam kondisi tetap aman maka ketinggian kolom air dibuat setinggi $8,59 \mathrm{~cm}$.

\section{DAFTAR PUSTAKA}

[1] Imam Kloliq Muharom, 2015. Analisis Perencanaan Reaktor Biogasn Kap 16 M2 Dengan Pemanfaatan Kotoran Manusia Jemis Vol ; 3 No.2 Universitas ... Putro Jurusan Tehnik Mesin Surabaya Indonesia.

[2] M.C Tri Atmodjo, . Perancangan Tangki Biogas Portabel Sebagai Sarana Produksi Energi Alternatif Di Pedesaan Balai Desa Tehnologi Pati Lampung Badan Pengharapan dan Penerapan Tehnologi.

[3] Raldi Antono, 2017. Kuestor Proposal Limbah Sapi Untuk Biogas Dan Listrik . Sumber: Https/Koester Wardpass.Com/Bisnis/Proposal-Limbah-Sapi Untuk Biogas Dan Listrik.

[4] Y. Sulistyiyanto Dkk., 2006. Pemanfaatan Kotoran Sapi Sapi Sebagai Sumber Biogas Rumah Tangga Di Kabupaten Julang Pisau Propensi Kalimantan Tengah. Jurnal Widoyono Mengabdi. Volume 15 Nomor 2. 